\title{
Illustrating a new global-scale approach to estimating potential reduction in fish species richness due to flow alteration
}

\author{
S. Yoshikawa ${ }^{1}$, A. Yanagawa ${ }^{1}$, Y. Iwasaki ${ }^{1}$, P. Sui ${ }^{1}$, S. Koirala ${ }^{2}$, K. Hirano ${ }^{1}$, A. Khajuria ${ }^{1}$, R. Mahendran ${ }^{2}$, \\ Y. Hirabayashi ${ }^{2}$, C. Yoshimura ${ }^{1}$, and S. Kanae ${ }^{1}$ \\ ${ }^{1}$ Department of Civil Engineering, Tokyo Institute of Technology, Tokyo, Japan \\ ${ }^{2}$ Institute of Engineering Innovation, The University of Tokyo, Tokyo, Japan
}

Correspondence to: S. Yoshikawa (sayajo@ chikyu.mei.titech.ac.jp)

Received: 31 May 2013 - Published in Hydrol. Earth Syst. Sci. Discuss.: 20 June 2013

Revised: 27 December 2013 - Accepted: 6 January 2014 - Published: 19 February 2014

\begin{abstract}
Changes in river discharge due to human activities and climate change would affect the sustainability of freshwater ecosystems. To globally assess how changes in river discharge will affect the future status of freshwater ecosystems, global-scale hydrological simulations need to be connected with a model to estimate the durability of freshwater ecosystems. However, the development of this specific modelling combination for the global scale is still in its infancy. In this study, two statistical methods are introduced to link flow regimes to fish species richness (FSR): one is based on a linear relationship between FSR and mean river discharge (hereafter, FSR-MAD method), and the other is based on a multi-linear relationship between FSR and ecologically relevant flow indices involving several other flow characteristics and mean river discharge (FSR-FLVAR method). The FSRMAD method has been used previously in global simulation studies. The FSR-FLVAR method is newly introduced here. These statistical methods for estimating FSR were combined with a set of global river discharge simulations to evaluate the potential impact of climate-change-induced flow alterations on FSR changes. Generally, future reductions in FSR with the FSR-FLVAR method are greater and much more scattered than with the FSR-MAD method. In arid regions, both methods indicate reductions in FSR because mean discharge is projected to decrease from past to future, although the magnitude of reductions in FSR is different between the two methods. In contrast, in heavy-snow regions a large reduction in FSR is shown by the FSR-FLVAR method due to increases in the frequency of low and high flows. Although further research is clearly needed to conclude which method is more appropriate, this study demonstrates that the
\end{abstract}

FSR-FLVAR method could produce considerably different results when assessing the global role of flow alterations in changing freshwater ecosystems.

\section{Introduction}

In the attempt to define planetary boundaries, Rockström et al. (2009) identified the collapse of freshwater ecosystems as one of the most serious threats to the sustainability of the global freshwater systems. They discussed the collapse of freshwater ecosystems mainly in terms of global freshwater use, one of ten proposed indices of the planetary boundaries. However, two of the ten indices, biodiversity loss and climate change, are undoubtedly linked to the collapse of freshwater ecosystems. Rockström et al. (2009) adopted a concept proposed by Smakhtin et al. (2004) and Smakhtin (2008) in which $20-50 \%$ of mean annual river discharge (hereafter, MAD) is assigned as environmental flow to sustain freshwater ecosystem functioning. Hanasaki et al. (2008a, b) similarly but differently estimated a globally distributed monthly environmental flow requirement depending upon the climatic classification of each region. Such values have been estimated, but without considering explicit linkages to freshwater ecosystem structures and functions. There is a strong need to find ways to incorporate this linkage in order to more adequately determine environmental flows for each region at a global scale. 
Freshwater biodiversity has been lost more rapidly than terrestrial or marine biodiversity over the past $30 \mathrm{yr}$ (Jenkins, 2003; Butchart et al., 2010), possibly due to human activities and global climate change. The long-term trend of declining biodiversity in freshwater ecosystems is caused by multiple anthropogenic impacts such as water extraction and transfer, water pollution, and invasive species (Postel and Richter, 2003; IUCN, 2010). Furthermore, climate change would affect freshwater ecosystems not only by increasing temperatures but also by altering river discharge (López-Moreno et al., 2013) and other flow characteristics. Flow alteration limits the distribution and abundance of freshwater species and regulates the ecological integrity of a flowing water system (Poff et al., 1997).

To link flow regimes to freshwater biodiversity, Xenopoulos et al. (2005) established a linear relationship between fish species richness (FSR) and MAD. By applying this relationship to outputs of a global hydrological model, Xenopoulos et al. (2005) and Döll and Zhang (2010) showed the impact of anthropogenic alteration of river flow regimes on potential changes in the number of fish species. However, in dealing with FSR, indices based only on MAD would not be sufficient. Thus, Iwasaki et al. (2012) derived another multi-regression-based relationship of FSR in rivers worldwide to ecologically relevant flow indices involving not only MAD but also other flow characteristics. Given the likely impacts of changes in various flow characteristics on freshwater ecosystems, it should be useful to apply the relationship obtained by Iwasaki et al. (2012) to estimate a global-scale future reduction in FSR.

This paper presents the first attempt to combine each of two methods (namely the statistical methods of Iwasaki et al., 2012 and Xenopoulos et al., 2005) with a set of globalscale hydrological simulations, respectively. As an example of this application, we show the potential impact of climatechange-induced flow alterations on FSR changes in 84 individual river basins worldwide. Our intention here is not to provide a definitive result regarding the impact of climate change on freshwater ecosystems, but to show similarities and differences in the outputs of the two different methods. The results could aid in selecting an appropriate method for estimating threats to freshwater ecosystems.

\section{Data and methodology}

\subsection{Data}

We used a set of simulated daily river discharge data for which river routing was computed by a global river routing model (Hirabayashi et al., 2013), the Catchment-based Macro-scale Floodplain (CaMa-Flood) model (Yamazaki et al., 2011), using latest outputs of 11 coupled atmosphereocean general circulation models (AOGCMs). As shown by Yamazaki et al. (2011), the CaMa-Flood model more reason- ably represents temporal peaks in river discharge, as compared to previous global river routing models (Miller et al., 1994; Oki et al., 1999), because it adopts a diffusive equation and represents inundation dynamics. In this study, we used the simulation forced only by the representative concentration pathway (RCP) 8.5 scenario, which is characterized by increasing greenhouse gas emissions over time.

From the entire simulation period, $15 \mathrm{yr}$ periods from 1971 to 1985 and 2036 to 2050 were selected to represent the "past" and "future", respectively. For these target periods, at least $15 \mathrm{yr}$ of data were required. Following Kennard et al. (2010), Iwasaki et al. (2012) formulated their method using discharge data for a $15 \mathrm{yr}$ period. Kennard et al. (2010) showed that the performance of hydrologic metrics stabilizes when the data period is $15 \mathrm{yr}$ or longer (Fig. 3 in Kennard et al., 2010).

The current CaMa-Flood model does not account for the effects of anthropogenic water use and regulation such as irrigation from river sources and dam operations. Additionally, we did not apply any bias correction to the outputs of AOGCMs in this study, which could require additional computational resources. Nevertheless, the difference in the estimated FSRs between Xenopoulos's method based only on MAD (hereafter, FSR-MAD method) and Iwasaki's method based on both MAD and some indices of daily flow variation (hereafter, FSR-FLVAR method) would show meaningful implications.

We obtained gauge-based daily river discharge data from the Global Runoff Data Centre (GRDC) to compare the simulated data with observed data. The catchment area and latitude of each station where river discharge was measured were also obtained from the GRDC database to calculate FSR using the FSR-FLVAR method.

\subsection{Selected individual river basins}

We selected 84 individual river basins out of 6158 gauging stations in the GRDC using the following four criteria. A distribution map of the 84 individual river basins is provided in Fig. 1.

1. Avoid gauging stations at which simulated and observed river discharge data differ by two orders of magnitude.

2. Avoid river basins with characteristics that have not yet been robustly represented in the CaMa-Flood river routing model. For example, the model cannot represent seasonal variation in river discharge in dry rivers in flat topography. The limitation is caused by the current status of elevation data, in which values are integers. Therefore, the accuracy of flow direction calculations in flat regions remains a challenging issue.

3. Following Iwasaki et al. (2012), avoid selecting river basins where the catchment area (i.e., provided by 


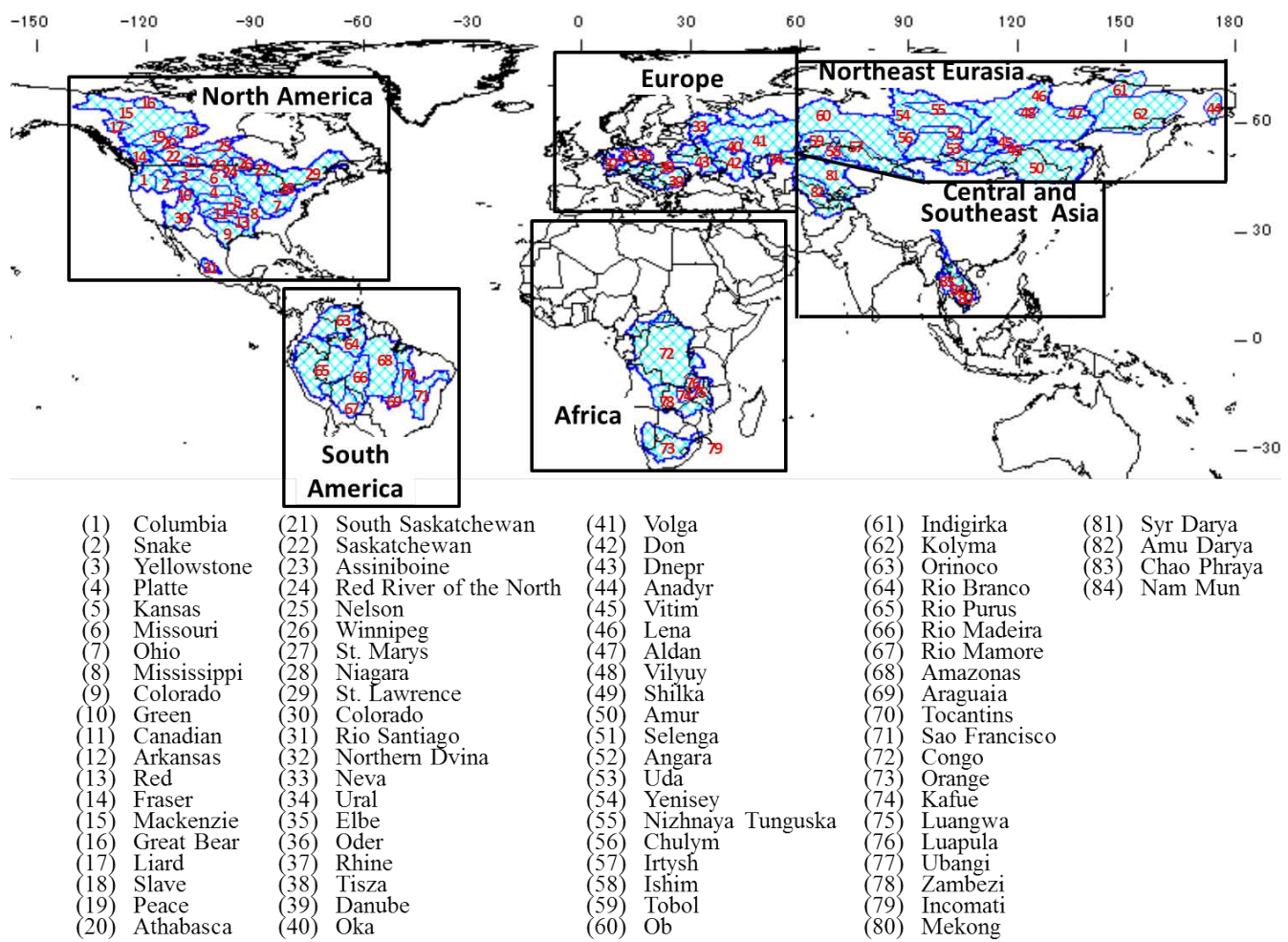

Fig. 1. Eighty-four river basins selected to evaluate future reductions in fish species richness. Basin map with locations of the 84 individual river basins indicated by numbers.

GRDC) makes up less than $50 \%$ of total basin area (i.e., estimated in Tockner et al., 2008; Lehner et al., 2008). Here, the catchment area and the total basin area represent the areas of land drained by the upstream of river from the gauging station and river mouth.

4. Again, following Iwasaki et al. (2013), avoid using several gauging stations along the same river to provide robustness and diversity. In this study, the gauging station with the largest upstream catchment area was selected.

\subsection{Basin-scale fish species richness}

Mean river discharge (MAD) at the river outlet has been well related to basin-scale FSR on global (Oberdorff et al., 1995, 2011) and continental scales (Livingstone et al., 1982; Hugueny, 1989). Hugueny et al. (2010) suggested that MAD is a reasonable predictor of the log-log linear relationship with which to obtain basin-scale FSR. Conceptually, river discharge is a proxy of the habitat size of fishes (Hugueny et al., 2010; Oberdorff et al., 2011).

According to these previous studies, Xenopoulos et al. (2005) calculated future reductions in FSR on the global scale. They combined the species-discharge relationship with projected losses in river discharge due to climate change using the MAD method as follows:

$\mathrm{FSR}=\exp (0.4 \times \log -\mathrm{MAD}+0.6242)$.

The species-discharge relationship may be the best approach available for projecting future reductions in FSR (Xenopoulos and Lodge, 2006), and only mean river discharge was considered in the above studies, as well as by Döll and Zhang (2010). However, the flow can be described from five ecologically relevant aspects of its regime (magnitude, frequency, duration, timing and rate of change of flow events) (Richter et al., 1996; Poff et al., 1997), and a number of flow indices have been proposed to be ecologically important (Olden and Poff, 2003; Richter et al., 1996). Therefore, not only mean river discharge, but other flow characteristics (e.g. high/low flows and flow variation) could play a vital role in sustaining freshwater ecosystems (Acreman and Dunbar, 2004; Poff et al., 1996). A considerable challenge for quantitative associations of these flow characteristics with ecological indicators such as FSR is incorporating them into a future projection of hydrology.

More recently, Iwasaki et al. (2012) calculated a comprehensive set of 36 flow metrics belonging to 5 aspects of flow regime based on daily discharge data observed at the outlets of 72 rivers worldwide, and statistically estimated relationships between the flow metrics and basin-scale FSR. The study provided the first empirical evidence that specific 
low- and high-flow characteristics may be necessary to predict basin-scale FSR using the FSR-FLVAR method as expressed by Eq. (2):

$$
\mathrm{FSR}=\exp \left(\begin{array}{l}
3.948-0.03420 \times \mathrm{LAT}+0.2732 \times \mathrm{AREA} \\
+0.3734 \times \mathrm{log}-\mathrm{MAD}-1.573 \times \mathrm{FL} 2 \\
+0.8318 \times \mathrm{TH} 3-0.1163 \times \mathrm{TL} 2
\end{array}\right),
$$

where LAT, AREA, log-MAD, FL2, TH3, and TL2 are described in Table 1.

It should be noted that we used these two methods to predict the only reduction in FSR, following previous studies (e.g., Döll and Zhang, 2010; Xenopoulos and Lodge, 2006; Xenopoulos et al., 2005). This is mainly because increases in FSR due to evolution likely require a longer time (see Xenopoulos et al., 2005 for a more detailed discussion), although positive effects of future changes in river discharge would be expected. Also, future projections based on the two methods ignore the timescale of species loss and merely produce the number of fish species committed to extinction (Tedesco et al., 2013).

\section{Results}

Future reductions in FSR due to climate change were computed using both the FSR-MAD and FSR-FLVAR methods. The global distributions of median values of the future reduction in FSR in 84 individual river basins are presented in Fig. 2a (by the FSR-MAD method) and Fig. 2b (by the FSR-FLVAR method). A scatter diagram of median values by two methods is also shown in Fig. 2c. Because the FSRFLVAR method (i.e., Iwasaki et al., 2012) took into account not only MAD but also flow indices obtained from temporal variation in daily river discharge, such as the frequency of low-flow, Fig. $2 \mathrm{a}$ and $\mathrm{b}$ have different spatial patterns. The FSR-FLVAR method tends to show a larger reduction in FSR in each basin. In addition to the spatial distribution, we also illustrate the range/spread of reductions in FSR among 11 AOGCMs for each basin by showing their box plots (Fig. 3). The spread of the reduction was generally much greater using the FSR-FLVAR method, likely due to the incorporation of more aspects of river discharge data in addition to mean discharge.

In the FSR-MAD method (Fig. 2a), 32 of the 84 basins would suffer from a reduction in FSR when comparing the medians of the 11 results among AOGCMs. Reductions of more than $5 \%$ were limited to the Red River basin ( $8 \%$ ), the Kansas, Platte, Colorado, Canadian and Arkansas basins $(7 \%)$, and the Danube (5\%). Reductions in FSR are only shown in semi-arid regions of central and southern North America and central south Europe. Thus, potential reductions in FSR due to climate change are not detected in Northern Eurasia, southern Africa, eastern Europe, South America, Southeast Asia, or northern and eastern North America. On average, the median value of FSR decreased by $3 \%$. The heights of box plots (75th-25th percentiles) showing FSR reductions are projected to be about -15 to $0 \%$ (blue box plot in Fig. 3).

In the FSR-FLVAR method (Fig. 2b), 36 of the 84 total basins would experience decreased FSR if comparing the medians of the 11 results. Some of the median values of reduction in FSR were greater than $10 \%$, such as $40 \%$ in the Nelson, $21 \%$ in the Mackenzie, 20\% in the Winnipeg, $18 \%$ in the Ob, $16 \%$ in the Arkansas and Saskatchewan, and $13 \%$ in the Syr Darya and Incomati basins (Fig. 2b). The reductions in FSR are projected across basins in North America, South America, Northeast Eurasia, Central Asia and southern Africa, especially in heavy-snow or semi-arid regions. On average, the median value of FSR decreases by $8 \%$. The heights of the box plots are projected to be about -55 to $0 \%$ (pink box plot in Fig. 3). The ranges of the reductions are spread over several rivers (the Platte, Arkansas, and St. Lawrence rivers in North America, and the Amu Darya River in Central Asia).

Overall, we briefly summarize the differences in FSR reductions between the FSR-MAD and FSR-FLVAR methods as follows. The future reductions predicted by the FSRFLVAR method were generally greater than those predicted by the FSR-MAD method. Additionally, the FSR-FLVAR method showed a wider spread ( -55 to $0 \%$ ) of reductions among the 11 AOGCMs compared to the FSR-MAD method $(-15$ to $0 \%)$. In semi-arid regions such as South America, the central United States, southern Africa and Central Asia, both methods projected reductions in FSR, but with different magnitudes of decrease. In heavy-snow regions of Northeast Eurasia and North America, the FSR-FLVAR method indicated significant reductions in FSR, whereas the FSR-MAD method showed only minor reductions.

\section{Discussion and concluding remarks}

In this study, we projected and compared future reductions in FSR based on simulated river discharge due to climate change using two statistical methods. The FSR-FLVAR method, in which both MAD and flow variation were used to predict FSR, showed larger and more widely spread reductions in FSR in most river basins, compared to results from the FSR-MAD method that were only based on MAD.

In South America, the semi-arid region of North America, southern Africa and Central Asia, both methods projected reductions in FSR but with different magnitudes and spreads. In these regions, log-MAD (for greater detail see Appendix A, including Fig. A1) decreased from the past to future, implying that the decrease in total discharge due to climate change was commonly responsible for the projected reductions in FSR. In addition, the obvious differences in the magnitudes and spreads between the two methods could be due to changes in flow indices except for mean discharge 
Table 1. List of flow metrics and definitions used in the FSR-FLVAR method.

\begin{tabular}{ll}
\hline Metrics & Definitions \\
\hline LAT & Absolute value of latitude at the river outlet (degree) \\
AREA & $\log _{10}$-transformed catchment area $\left(\mathrm{km}^{2}\right)$ \\
log-MAD & $\log _{10}$-transformed mean annual discharge (MAD) $\left(\mathrm{m}^{3} \mathrm{~s}^{-1}\right)$ \\
FL2 & Coefficient of variation $(\mathrm{CV})$ in frequency of low flow $(25$ th percentile) \\
TH3 & Maximum proportion of the year (number of days/365) during which no \\
& 1.67 yr floods have ever occurred \\
TL2 & CV in the Julian date of annual minimum flow \\
\hline
\end{tabular}

(Figs. A2-A4), as only the FSR-FLVAR method was sensitive to those indices.

In heavy-snow regions of Northeast Eurasia and North America such as the Nelson, Mackenzie, Ob and Saskatchewan basins, reductions in FSR predicted by the FSR-FLVAR method are much higher than those by the FSRMAD method. In these regions, although increases in annual precipitation and discharge are projected (Hirabayashi et al., 2013), the frequencies of low and high flows are projected to increase. Therefore, increases in FL2 and TL2 (for additional details see Appendix A, including Figs. A2 and A4) were likely responsible for the reduction in FSR projected by the FSR-FLVAR method. This result suggests that FSR is affected by higher river flows in winter, earlier spring flows, and reduced summer low flows that can be caused by warmer and shorter snow seasons in the future. Battin et al. (2007) also indicated that highly increased winter peak flows might lead to a decline in fish populations in the Pacific Northwest region of the United States. In addition, changes in flow indices and MAD could have caused larger spreads in the outputs of the FSR-FLVAR method.

One of the drawbacks of this study involved the simulated river discharge data in our framework, such as biases in the runoff data from the 11 AOGCMs, which were used in only one scenario, and thus there is a need for better calibration of the CaMa-Flood model. In addition, Döll et al. (2009) argued that river flow alterations during the past decades have been largest in semi-arid regions with extensive irrigation and large dams in downstream areas. Although the impact assessment of water use such as irrigation is beyond the scope of this paper, we performed simple sensitivity experiments to examine the impact of water use on estimated FSR by using the two methods (see details in Appendix B). Here, we took the Syr Darya basin as an example, where river discharge can be strongly affected by human activities. When total river discharge for the period 1971 to 1985 was reduced by $82 \%$ and low- and high-flow characteristics were also changed, the FSRs projected by the FSR-MAD and FSR-FLVAR methods were reduced by 24 and $37 \%$, respectively. FSR calculated by the FSR-FLVAR method were generally more sensitive than those predicted by the FSR-MAD method. For comprehensive future assessments, the impacts of water use and river regulation should be incorporated into this framework, as was done in global-scale water resource models, accounting for the effects of anthropogenic water use and dam regulation (Biemans et al., 2011; Döll et al., 2009; Hanasaki et al., 2013; Wada et al., 2011; Wisser et al., 2010; Yoshikawa et al., 2013).

The period of river discharge data should also be long enough to evaluate flow characteristics. In this study, we assumed that the application of the longer period (i.e., more than $15 \mathrm{yr}$ ) would not materially affect our results because the FSR-FLVAR method was formulated using observed discharge data for a $15 \mathrm{yr}$ period by Iwasaki et al. (2012). Flow metrics calculated from longer river discharge data (e.g. 30 and $50 \mathrm{yr}$ ) might be more appropriate as they could be ecologically, climatologically and hydrologically more representative of flow regime. In addition, a $15 \mathrm{yr}$ period from 2036 to 2050 was selected to represent as the "future", but the climate change signal may still be weak in this period. We would investigate other time slices in upcoming papers.

There is also uncertainty in the estimation of FSR based on only river discharge. Both the FSR-MAD and FSR-FLVAR methods were solely based on statistical regression (not causal relationships) between flow metrics and FSR. In addition, these methods did not consider the impact of other physical (e.g., damming, water temperature), chemical (e.g., water pollution) and biological factors (e.g., invasive species) that should affect basin-scale FSR (see for example Vörösmarty et al., 2010). Incorporation of these factors into predictions of future reductions in FSR is critically important but still challenging. Also, Iwasaki et al. (2012) advocated that more careful selection of flow metrics is needed. Flow metrics are generally calculated and used as small-scale (such as reach-scale) indicators of flow regimes. Thus, the appropriateness of using river discharge at the river outlet as an ecological representative of an entire river basin is uncertain (Iwasaki et al., 2012), and an assessment of longitudinal variation in flow regimes would be valuable.

Despite the drawbacks and uncertainties discussed above, this study shows the impact of taking flow variation into account in a global-scale assessment of freshwater biodiversity under global environmental changes. There were considerable differences in the results between the FSR-MAD and 


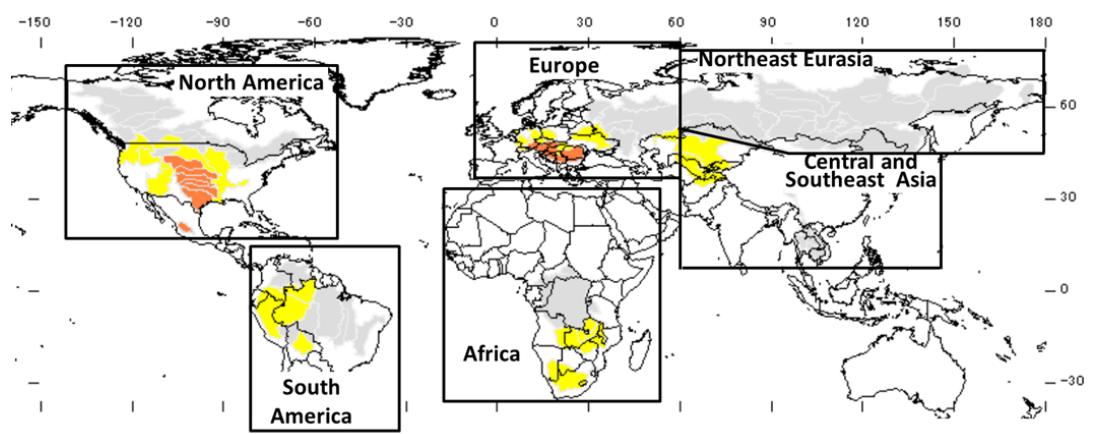

(a)

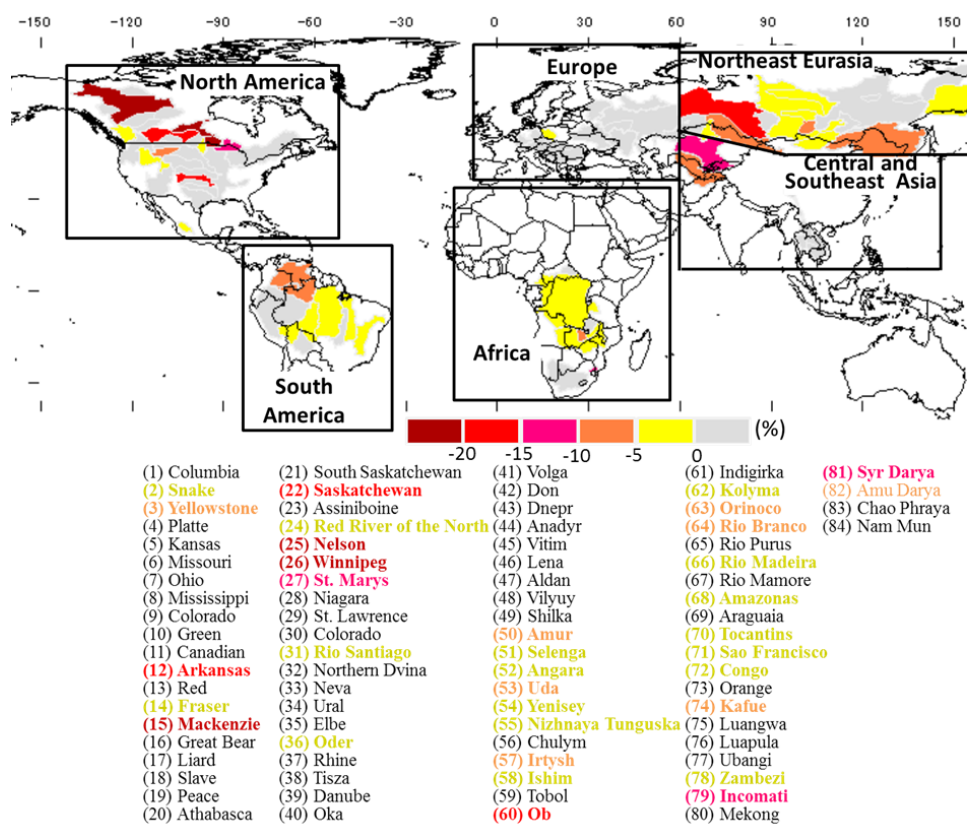

(b)

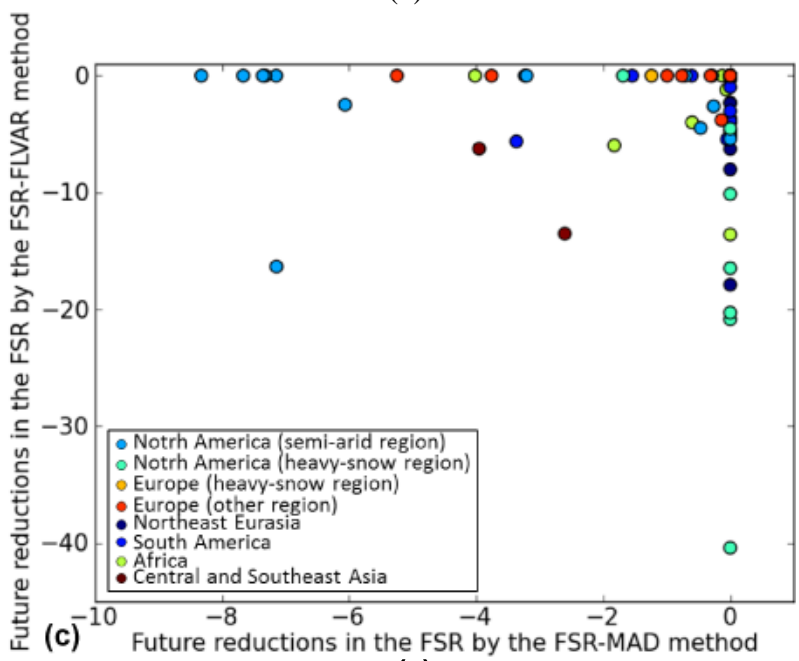

(c)

Fig. 2. Global distributions of the median value of future reductions in fish species richness in 84 individual river basins by (a) the FSR-MAD and (b) the FSR-FLVAR methods. (c) Values in (a) and (b) are converted into scatter diagram. 


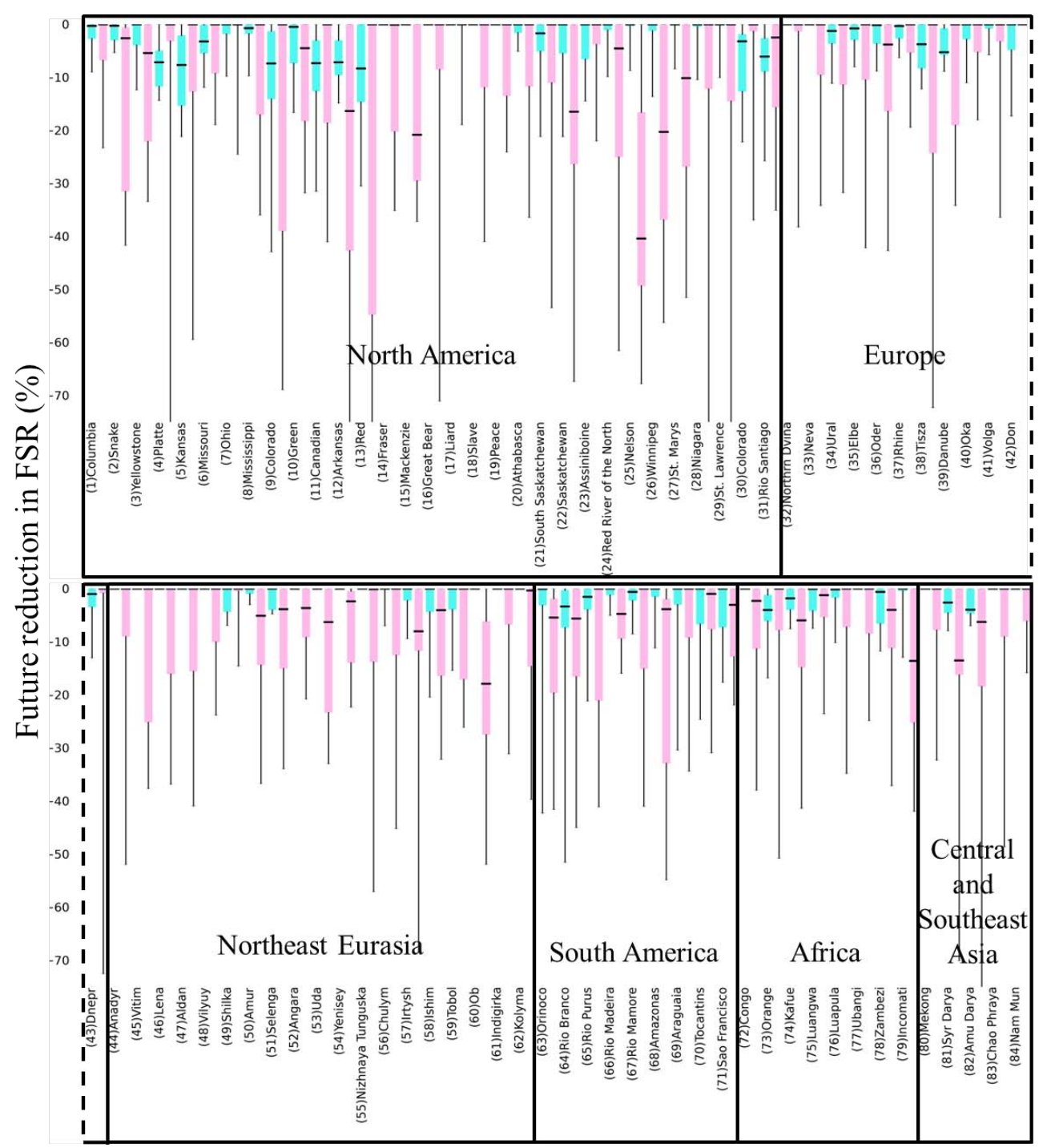

Fig. 3. Box plot of the median values of future reductions in FSR (\%) by the FSR-MAD (blue box) and FSR-FLVAR methods (pink box) in the 84 individual river basins. The height of each box indicates the interquartile range (75th-25th percentiles) and the bold line within each box indicates the median value. The solid thin lines represent the maximum and minimum of the reduction in FSR for all of the atmosphere-ocean general circulation models.

FSR-FLVAR methods. Even if the direction of change was similar, the magnitude and spread of change were different between the two methods. We found that vulnerable regions that were easily affected by climate change through future reductions in FSR as predicted by the FSR-FLVAR method were notably different from those that were predicted by the FSR-MAD method, such as snowy regions. Although we cannot determine only by this study which prediction is more reliable, it can be argued that efforts to take plural ecologically relevant flow indices into account would lead to more appropriate methods for estimating potential changes in fish species richness. We believe this study is one of such efforts at an early development stage.

\section{Appendix A}

\section{Results of 4 flow metrics in each of the 11 coupled atmosphere-ocean general circulation models}

Four flow metrics (log-MAD, FL2, TH3 and TL2) were computed, and their magnitudes were compared between past and present periods to identify the impact of climate change. Overall, there was no noticeable difference in log-MAD between past and future (Fig. A1). However, there were obvious changes in FL2, TH3 and TL2 (Figs. A2, A3 and A4). 


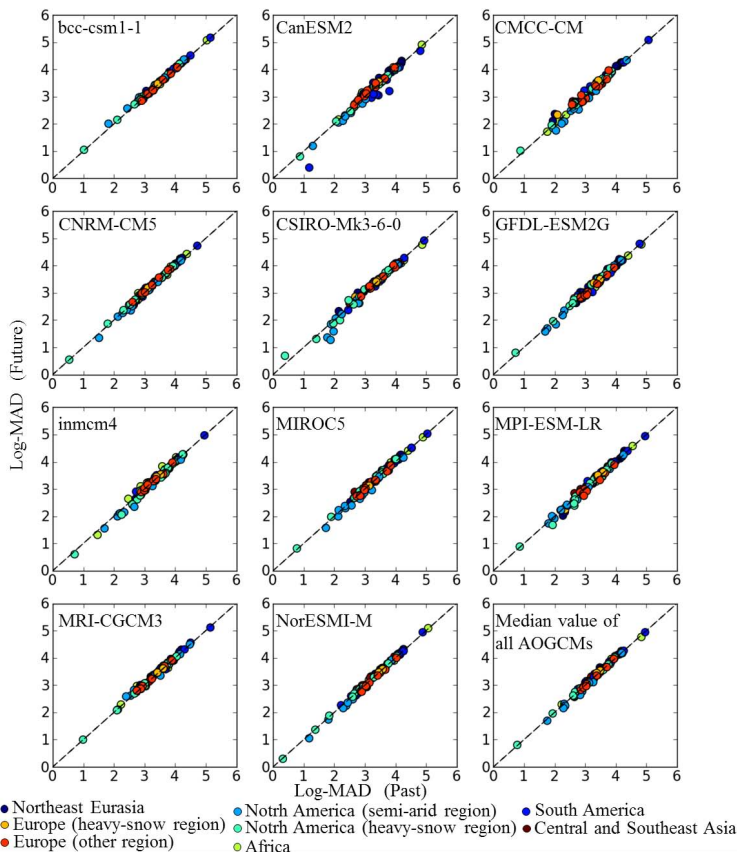

Fig. A1. Comparisons of mean river discharge (log-MAD) between past and future in each of the 11 coupled atmosphere-ocean general circulation models.

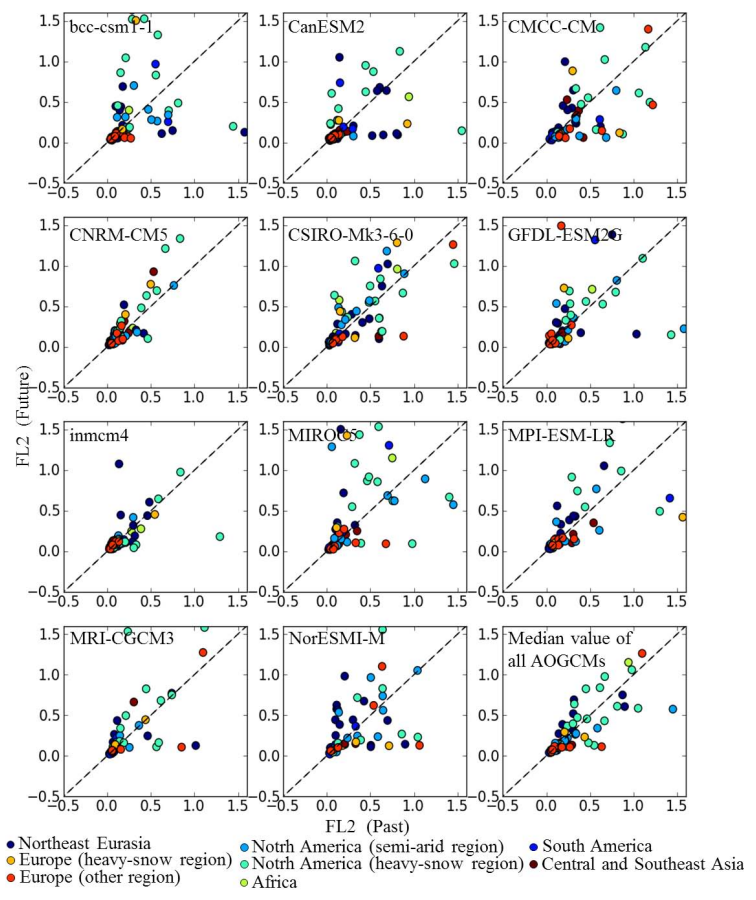

Fig. A2. Comparisons of the coefficient of variation of low flow (FL2) between past and future in each of the 11 coupled atmosphere-ocean general circulation models.

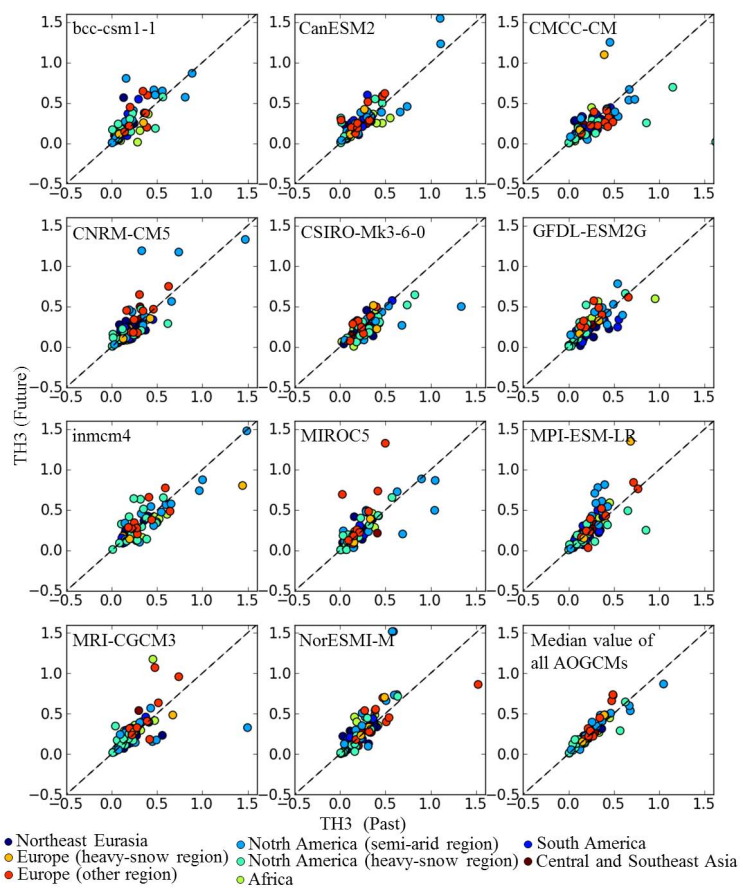

Fig. A3. Comparisons of the maximum proportion of the year during which no $1.67 \mathrm{yr}$ floods have ever occurred (TH3) between past and future in each of the 11 coupled atmosphere-ocean general circulation models.

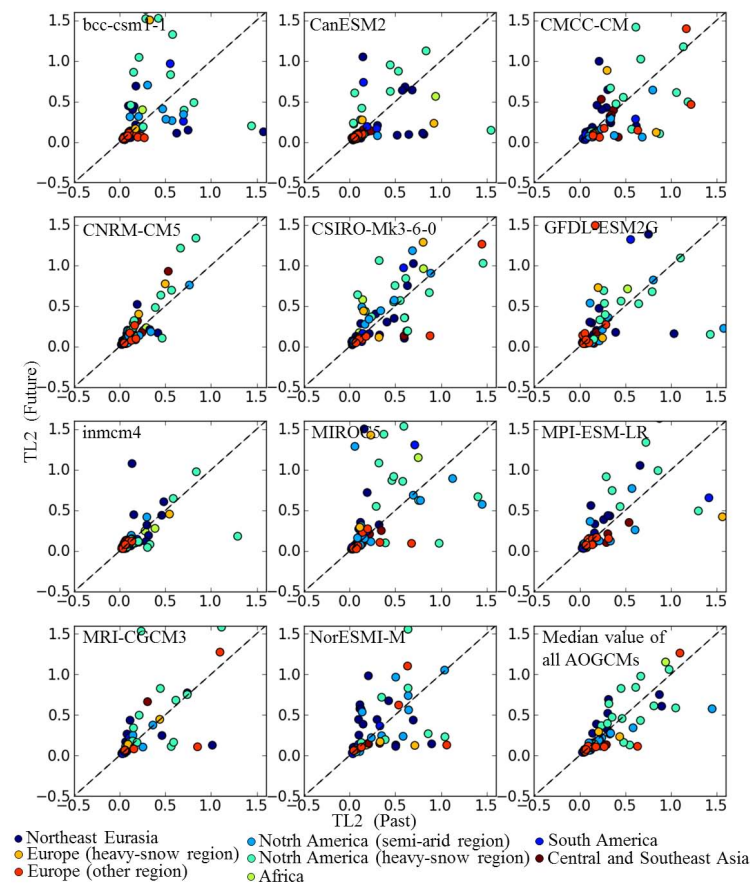

Fig. A4. Comparisons of the coefficient of variation in the Julian date of annual minimum flow (TL2) between past and future in each of the 11 coupled atmosphere-ocean general circulation models. 


\section{Appendix B}

\section{Case-study sensitivity analysis}

We used gauge-based daily river discharge data from the GRDC to test the impact of variation in the two methods on estimated FSR. This approach was used to investigate estimation uncertainty and parameter sensitivity by applying anthropogenic water use and regulation to river discharge. For the sensitivity analysis, we used data from the Syr Darya river basin from the period 1971 to 1985 . Gauge-based total river discharge was reduced to $82 \%$ of simulated total river discharge in each of the 11 AOGCMs. In the FSR-MAD and FSR-FLVAR methods, FSR calculated using the gauge-based river discharge decreased by 24 and $37 \%$, respectively, compared to FSR calculated using simulation-based river discharge among the 11 AOGCMs.

Acknowledgements. We gratefully acknowledge three anonymous reviewers for providing invaluable comments and suggestions. Our special thanks go to the Global Runoff Data Centre for providing valuable data. Last but not least, this study was supported by the Core Research for Evolutional Science and Technology (CREST), the Japan Science and Technology Agency, the Funding Program for the Next Generation of World-leading Researchers, the Japan Society for the Promotion of Science, and JSPS KAKENHI Grant-in-Aid for Scientific Research (C) Number 24560617.

Edited by: D. Gerten

\section{References}

Acreman, M. C. and Dunbar, M. J.: Defining environmental river flow requirements - a review, Hydrol. Earth Syst. Sci., 8, 861876, doi:10.5194/hess-8-861-2004, 2004

Battin, J., Wiley, M. W., Ruckelshaus, M. H., Palmer, R. N., Korb, E., Bartz, K. K., and Imaki, H.: Projected impacts of climate change on salmon habitat restoration, Proc. Natl. Acad. Sci., 104, 6720-6725, 2007.

Biemans, H., Haddeland, I., Kabat, P., Ludwig, F., Hutjes, R. W., Heinke, J., von Bloh, W., and Gerten, D.: Impact of reservoirs on river discharge and irrigation water supply during the 20th century, Water Resour. Res., 47, 1-15, 2011.

Butchart, S. H. M., Walpole, M., Collen, B., van Strien, A., Scharlemann, J. P. W., Almond, R. E. A., Baillie, J. E. M., Bomhard, B., Brown, C., Bruno, J., Carpenter, K. E., Carr, G. M., Chanson, J., Chenery, A. M., Csirke, J., Davidson, N. C., Dentener, F., Foster, M., Galli, A., Galloway, J. N., Genovesi, P., Gregory, R. D., Hockings, M., Kapos, V., Lamarque, J.-F., Leverington, F., Loh, J., McGeoch, M. A., McRae, L., Minasyan, A., Morcillo, M. H., Oldfield, T. E. E., Pauly, D., Quader, S., Revenga, C., Sauer, J. R., Skolnik, B., Spear, D., Stanwell-Smith, D., Stuart, S. N., Symes, A., Tierney, M., Tyrrell, T. D., Vie, J.-C., and Watson, R.: Global Biodiversity: Indicators of Recent Declines, Science, 328, 1164 $1168,2010$.
Döll, P. and Zhang, J.: Impact of climate change on freshwater ecosystems: a global-scale analysis of ecologically relevant river flow alterations, Hydrol. Earth Syst. Sci., 14, 783-799, doi:10.5194/hess-14-783-2010, 2010.

Döll, P., Fiedler, K., and Zhang, J.: Global-scale analysis of river flow alterations due to water withdrawals and reservoirs, Hydrol. Earth Syst. Sci., 13, 2413-2432, doi:10.5194/hess-13-24132009, 2009.

Hanasaki, N., Kanae, S., Oki, T., Masuda, K., Motoya, K., Shirakawa, N., Shen, Y., and Tanaka, K.: An integrated model for the assessment of global water resources - Part 2: Applications and assessments, Hydrol. Earth Syst. Sci., 12, 1027-1037, doi:10.5194/hess-12-1027-2008, 2008a.

Hanasaki, N., Kanae, S., Oki, T., Masuda, K., Motoya, K., Shirakawa, N., Shen, Y., and Tanaka, K.: An integrated model for the assessment of global water resources - Part 1: Model description and input meteorological forcing, Hydrol. Earth Syst. Sci., 12, 1007-1025, doi:10.5194/hess-12-1007-2008, 2008b.

Hanasaki, N., Fujimori, S., Yamamoto, T., Yoshikawa, S., Masaki, Y., Hijioka, Y., Kainuma, M., Kanamori, Y., Masui, T., Takahashi, K., and Kanae, S.: A global water scarcity assessment under Shared Socio-economic Pathways - Part 2: Water availability and scarcity, Hydrol. Earth Syst. Sci., 17, 2393-2413, doi:10.5194/hess-17-2393-2013, 2013.

Hirabayashi, Y., Mahendran, R., Koirala, S., Konoshima, L., Yamazaki, D., Watanabe, S., Kim, H., and Kanae, S.: Global flood risk under climate change, Nat. Clim. Chang., 3, 816-821, doi:10.1038/nclimate1911, 2013.

Hugueny, B.: West African rivers as biogeographic islands: species richness of fish communities, Oecologia, 79, 236-243, 1989.

Hugueny, B., Oberdorff, T., and Tedesco, P. A.: Community ecology of river fishes: a large-scale perspective, in: Community Ecology of Stream Fishes: Concepts, Approaches, and Techniques, edited by: Gido, K. B. and Jackson, A. D., American Fisheries Society, Bethesda, Maryland, 29-62, 2010.

IUCN (the International Union for Conservation of Nature): An analysis of the status and distribution of freshwater biodiversity in Continental Africa on the IUCN Red List, available at: www.iucnredlist.org/freshwater (last access: 17 June 2013), 2010.

Iwasaki, Y., Ryo, M., Sui, P., and Yoshimura, C.: Evaluating the relationship between basin-scale fish species richness and ecologically relevant flow characteristics in rivers worldwide, Freshw. Biol., 57, 2173-2180, 2012.

Jenkins, M.: Prospects for biodiversity, Science, 302, 1175-1177, 2003.

Kennard, M. J., Mackay S. J., Pusey, B. J., Olden, J. D., and Marsh N.: Quantifying uncertainty in estimation of hydrologic metrics for ecohydrological studies, River. Res. Applic, 26, 137-156, 2010.

Lehner, B., Verdin, K., and Jarvis, A.: Hydrological data and maps based on Shuttle elevation derivatives, US Geological Survey, available at: http://hydrosheds.cr.usgs.gov/ (last access: 10 October 2013), 2008.

Livingstone, D. A., Rowland, M., and Bailey, P. E.: On the Size of African Riverine Fish Faunas, Am. Zool., 22, 361-369, 1982. 
López-Moreno, J. I., Vicente-Serrano, S. M., Zabalza, J., Beguería, S., Lorenzo-Lacruz, J., Azorin-Molina, C., and Morán-Tejeda, E.: Hydrological response to climate variability at different time scales: a study in the Ebro basin, J. Hydrol., 477, 175-188, 2013.

Miller, J. R., Russell, G. L., and Caliri, G.: Continental-scale river flow in climate models, J. Climate, 7, 914-928, 1994.

Oberdorff, T., Guégan, J.-F., and Hugueny, B.: Global scale patterns of fish species richness in rivers, Ecography, 18, 345-352, 1995.

Oberdorff, T., Tedesco, P. A., Hugueny, B., Leprieur, F., Beauchard, O., Brosse, S., and Dürr, H. H.: Global and regional patterns in riverine fish species richness: a review, Int. J. Ecol., 2011, 967631, doi:10.1155/2011/967631, 2011.

Oki, T., Nishimura, T., and Dirmeyer, P.: Assessment of annual runoff from land surface models using Total Runoff Integrating Pathways (TRIP), J. Meteorol. Soc. Jpn, 77, 235-255, 1999.

Olden, J. D. and Poff, N.: Redundancy and the choice of hydrologic indices for characterizing streamflow regimes, River Res. Appl., 19, 101-121, 2003.

Poff, N. L., Tokar, S., and Johnson, P.: Stream hydrological and ecological responses to climate change assessed with an artificial neural network, Limnol. Oceanogr., 41, 857-863, 1996.

Poff, N. L., Allan, J. D., Bain, M. B., Karr, J. R., Prestegaard, K. L., Richter, B. D., Sparks, R. E., and Stromberg, J. C.: The natural flow regime: a new paradigm for riverine conservation and restoration, Bioscience, 47, 769-784, 1997.

Postel, S. and Richter, B.: Rivers for life: managing water for people and nature, Island Press, Washington, DC, 2003.

Richter, B. D., Baumgartner, J. V., Powell, J., and Braun, D. P.: A method for assessing hydrologic alteration within ecosystems, Conserv. Biol., 10, 1163-1174, 1996.

Rockström, J., Steffen, W., Noone, K., Persson, A., Chapin, F. S., Lambin, E. F., Lenton, T. M., Scheffer, M., Folke, C., Schellnhuber, H. J., Nykvist, B., de Wit, C. A., Hughes, T., van der Leeuw, S., Rodhe, H., Sorlin, S., Snyder, P. K., Costanza, R., Svedin, U., Falkenmark, M., Karlberg, L., Corell, R. W., Fabry, V. J., Hansen, J., Walker, B., Liverman, D., Richardson, K., Crutzen, P., and Foley, J. A.: A safe operating space for humanity, Nature, 461, 472-475, 2009.

Smakhtin, V.: Basin Closure and Environmental Flow Requirements, Int. J. Water Resour. Develop., 24, 227-233, 2008.
Smakhtin, V., Revenga, C., and Döll, P.: A pilot global assessment of environmental water requirements and scarcity, Water Int., 29, 307-317, 2004.

Tedesco, P. A., Oberdorff, T., Cornu, J.-F., Beauchard, O., Brosse, S., Dürr, H. H., Grenouillet, G., Leprieur, F., Tisseuil, C., Zaiss, R., and Hugueny, B.: A scenario for impacts of water availability loss due to climate change on riverine fish extinction rates, $\mathrm{J}$. Appl. Ecol., 50, 1105-1115, 2013.

Tockner, K., Uehlinger, U., and Robinson, C. T.: Rivers of Europe, Elsevier/Academic Press, London, 2009.

Vörösmarty, C. J., McIntyre, P., Gessner, M. O., Dudgeon, D., Prusevich, A., Green, P., Glidden, S., Bunn, S. E., Sullivan, C. A., and Liermann, C. R.: Global threats to human water security and river biodiversity, Nature, 467, 555-561, 2010.

Wada, Y., van Beek, L. P. H., Viviroli, D., Dürr, H. H., Weingartner, R., and Bierkens, M. F. P.: Global monthly water stress: 2. Water demand and severity of water stress, Water Resour. Res., 47, W07518, doi:10.1029/2010WR009792, 2011.

Wisser, D., Fekete, B. M., Vörösmarty, C. J., and Schumann, A. H.: Reconstructing 20th century global hydrography: a contribution to the Global Terrestrial Network- Hydrology (GTN-H), Hydrol. Earth Syst. Sci., 14, 1-24, doi:10.5194/hess-14-1-2010, 2010.

Xenopoulos, M. A. and Lodge, D. M.: Going with the flow: using species-discharge relationships to forecast losses in fish biodiversity, Ecology, 87, 1907-1914, 2006.

Xenopoulos, M. A., Lodge, D. M., Alcamo, J., Marker, M., Schulze, K., and Van Vuuren, D. P.: Scenarios of freshwater fish extinctions from climate change and water withdrawal, Global Change Biol., 11, 1557-1564, 2005.

Yamazaki, D., Kanae, S., Kim, H., and Oki, T.: A physically based description of floodplain inundation dynamics in a global river routing model, Water Resour. Res., 47, W04501, doi:10.1029/2010WR009726, 2011.

Yoshikawa, S., Cho, J., Yamada, H. G., Hanasaki, N., Khajuria, A., and Kanae, S.: An assessment of global net irrigation water requirements from various water supply sources to sustain irrigation: rivers and reservoirs (1960-2000 and 2050), Hydrol. Earth Syst. Sci. Discuss., 10, 1251-1288, doi:10.5194/hessd-10-12512013, 2013. 